\title{
Connectivism in the Network Society. The Coming of Social Capital Knowledge
}

\author{
José Antonio Díaz Martínez \\ Departamento de Sociología III, UNED \\ jdiaz@poli.uned.es \\ Teodoro Hernández de Frutos \\ Departamento de Sociología, Universidad Pública de Navarra \\ theo@unavarra.es
}

\begin{abstract}
Connectivism is a hypothesis of learning which emphasizes the role of the social and cultural context. The relationship among work experience, learning and knowledge, as expressed in the concept of connectivity, is central to connectivism, motivating the name of the theory. According to the current status of online social network approaches, the interconnected computers increase the human intellect, because the network increases the cognitive capacity of individuals. The change in the role of knowledge that is taking place in society has to do with the relationship between technology and society. A collaborative group of knowledge building in the network is emerging as a result of the technological trends and culture. This article discusses the arrival of Virtual Communities of Building Knowledge (VCBK) as a phenomenon that appears spontaneously online. Traditional theories of learning and construction of knowledge have not taken into account the revolution that has occurred in recent decades due to the emergence of ICT. The connectivism refers to the knowledge in the network that arises from the interaction within a group of knowledge construction. In this paper, we consider some cases of VCBK: GNU/Linux, Wikipedia and MOOC. In VCBK, knowledge is created by the group. The sense or meaning created is the result of the group's dialogue.
\end{abstract}

Keywords: community, information, knowledge, network society, Internet, web, digital. 


\section{INTRODUCTION}

Many studies have highlighted the importance of information and communication technologies in the transformation of society, first, as a post-industrial society and, later, as an information or network society (Small et al., 2015, Brook et al., 2014, Zubcseka et al., 2014). Studies have always emphasised the strategic value of information and knowledge in the emerging society throughout. Research related the characteristics of the new economy and even the technological paradigm shift to the information technology (Tapscott and Williams, 2007), and many authors claim that the paradigm shift occurred shortly after the deployment of the new economy (Pérez, 2005). There are clear indications that major changes are taking place in Western societies as a result of the social application of ICT. Predictions are equally clear; the welfare and efficiency of the economic system depend on the reorganisation of the technological system and the development of areas of knowledge related to social innovation. According to Himanen (2005), the first phase of the information society focused on the development of technology, such as network connections. In the second phase, which has just begun, technological development will continue; however, the focus will shift to broader social issues, and the main focus will be on changing the ways in which we work.

Knowledge is a strategic element in the dominant economic model, and it has been like that for decades. The change in the role of knowledge that is taking place in society has to do with the relationship between technology and society. In the knowledge society, characterised by globalisation and networking technology, the process of knowledge creation is very important. We highlight two significant aspects of the process of knowledge construction: first, the creation of knowledge depends heavily on technological innovation; and second, social networks have become real tools of social knowledge creation. Thus, social networks can facilitate the transfer of knowledge, and, what is more important for my argument, they can facilitate the creation of knowledge. In the first case, we have a learning process, while, in the second, we have a process of knowledge development. In this sense, technology enables the creation of knowledge in society, and people move from being consumers of information and knowledge to being knowledge producers, active players in the process of the social construction of knowledge, which is why we discuss Virtual Communities of Building Knowledge (VCBK).

In the past decade, online education has emerged as a way for students and teachers to collaborate more freely, achieve greater flexibility and use new media to learn how to do it. The burning debate is whether online educational options are detrimental to traditional education or they are infinite advantages necessary to accommodate a twenty-first-century student. Advocates of virtual learning environments suggest that twen- 
ty-first-century students require the capabilities offered through Web 2.0 to succeed, while critics suggest that asynchronous interactions are not rigorous and attractive enough for the creation and construction of higher education. A balanced online environment should provide a combination of synchronous and asynchronous opportunities that promote communication and collaboration among peers and teachers (Reese, 2014).

\section{KNOWLEDGE DEPENDS HEAVILY ON TECHNOLOGICAL INNOVATION}

There are multiple ways of creating knowledge; traditionally, we consider the creation of knowledge through the reflection and creativity of individuals or through public debate and group reflection. However, there is another new medium for knowledge creation, which is a consequence of the interaction mediated by communication technologies. As Stahl points out, 'meaning is created across the utterances of different people'. That is, the meaning created is not a cognitive property of individual minds, but a characteristic of group dialogue (2006). The novel aspect of this medium is the ability to create knowledge through the network with the support of new technological tools, which makes the process of knowledge creation independent of space and time. Online interaction enables participants to share resources and to communicate and create social capital (Cachia et al., 2007). There is a difference between the learning process and the process of knowledge construction. 'Learning is an activity aimed at improving personal knowledge, whereas knowledge development puts innovation in the foreground' (YaoHong et al., 2010). Information is not knowledge. Information must be understood mainly as data and, through scientific organisation of data, it allows you to perform a sequence of actions. One example is computer systems that automate the processes of action: when they are given a particular situation, they perform a particular action. In fact, a computer program or an expert system responds automatically to a predetermined sequence. However, for knowledge, the action process is not predetermined. The probabilities of particular responses to certain situations can be calculated, but, in essence, knowledge building is an open process. As Downes (2011) says, knowledge is not the accumulation of a set of propositions, but the development of a pattern of connectivity in the brain. These patterns of connectivity correspond to the skills, abilities, intuitions and habits that we develop over time.

Engelbart's prediction was more or less focused on an isolated individual, but the revolution that is now taking place has more to do with the appreciation of the group and the community as an actor with intellectual capacity. Considering individualistic or personalistic approaches, the cultural and technological changes that are occurring in to- 
day's society strengthen the theories about the social network, people interaction, the community of interest and the thematic networks. One effect, perhaps unintended in the form that it takes today, is the emergence of strong social networks of knowledge. Thus, an updated approach to knowledge that considers the symbiosis or interaction between man and machine to improve the creation of knowledge communities is needed. The trends that are driving this transformation are the appreciation of the social and learning processes, the construction of a model of collaborative knowledge and the implementation of software to improve the interaction between people to facilitate the creation of knowledge (Stahl, 2006). In this context, connectivism appears as a technologically mediated link between a knowledge building network and a learning community.

Connectivism refers to the knowledge that emerges in the network from the interaction within a group of knowledge construction. This means that there is no knowledge of any of the nodes in the network; connectivism is the knowledge that emerges in the network, in the interaction between nodes, and transcends its members in a collaborative knowledge building process. This process should not be perceived as a deterministic development, it may arise spontaneously, but it is something that should be encouraged. It is a positive process that substantially increases the ability to create knowledge without the limitations of individual reflection or face-to-face relationships. In this sense, the use of current technology by small or large groups of knowledge can produce a kind of knowledge that cannot occur in other situations. In addition, the knowledge built through current technology occurs through a different process of building knowledge. In particular, I should mention the contribution of computers to the construction of knowledge. As Stahl (2006) points out, computer support can help us transcend the limits of individual cognition. It can facilitate the formation of small groups committed to deep knowledge building. It can empower such groups to construct forms of group cognition that exceed what the group members could achieve as individuals. This means that we have traditional processes of knowledge creation and new processes supported by technology that facilitate the interaction of groups focused on the creation of knowledge.

Traditional theories of learning and building knowledge have not taken into account the revolution that has occurred in recent decades due to the emergence of ICT. As a result of these processes, new answers to the classic questions of 'where does knowledge exist?' and 'how is it generated?' have emerged. Knowledge is, for connectivism, in the interaction that occurs in the network. Connectivity enhances the process of learning and knowledge building in the network society. We could say that connectivism in the virtual world is equivalent to face-to-face interactionism in the real world. However, connectivism has the additional feature of intermediation through technologies that enhance our own knowledge management capability. Intermediation can be configured in 
various ways; technology can be considered a mere facilitator of the relationship or it can be used to support and improve the process of building knowledge. In that sense, there is a type of interaction that occurs, or can occur, between people, between people and machines, and even between machines. A very important fact is that these machines have an ever-increasing level of ability. According to Downes (2012), connectivism is the knowledge distributed across a network of connections, and, therefore, learning consists in the ability to construct and go across those networks. It implies that the links must precede the linked parts, the laws of interaction must precede their content and the relations between the subjects must precede the subjects that are related (Marrero-Guillamón, 2012).

\section{VCBK: GNU/LINUX, WIKIPEDIA AND MOOC}

GNU/Linux is a program developed by a VCBK. This program is a clear example of the growing importance of collaborative work and knowledge communities. GNU/Linux has been developing for thirty years, essentially through a self-organised community of thousands of programmers who collaborate on ideas diversified in a constant exchange of open source code (YaoHong et al., 2010: 6). The free software movement is characterised by the adoption of an open structure and a philosophy that considers knowledge a common good. When Richard Stallman created the Free Software Foundation at the Artificial Intelligence Laboratory at MIT in 1985, he proclaimed the 'free communication and the use of software as an inalienable right'. This quote lays the foundations for what remains a very important collaborative work process for the development of an inclusive knowledge society and the democratisation of knowledge. This impulse was followed by Linus Torvalds, a Finnish programmer who created the GNU/ Linux software and promoted the hacker culture, and Ian Murdock, who created the Debian project in 1993. Currently, there are thousands of free software developers working under the guidance of the Debian Social Contract (2004) with the Free Software community to ensure the future development of this program in a $100 \%$ free quality way. At present, a significant number of computer systems incorporate GNU/Linux, respecting the open source rules.

There are millions of Linux users, and the number of them grows every day. The platforms using the Linux operating system was 4.8\% in February 2013 (w3schools. com, 2013). However, what really matters is the philosophy behind this movement, which emphasises open collaborative processes of building knowledge through VCBK, as well as many other movements that are emerging in today's knowledge society. Wiki- 
pedia is another example of VCBK. It is written collaboratively by Internet users. Anyone can write an article, even anonymously, and change existing articles. This contributes to the construction of knowledge that characterises the VCBK. Wikipedia has grown rapidly since its creation in 2001, attracting 470 million unique visitors monthly since February 2012 (Wikipedia 2012a). There are also more than 77,000 active contributors working on more than 22,0000,000 articles in 285 languages. There are 4,207,328 articles in English until now. Every day, hundreds of thousands of visitors from around the world collectively make tens of thousands of edits and create thousands of new articles to augment the knowledge held by the Wikipedia encyclopedia (Wikipedia, 2012b).

Wikipedia arises spontaneously in the virtual space, without a set plan, thanks to the possibilities of the network and the new culture or philosophy of collaborative Internet users turned into knowledge producers. 'As Wikipedia grew and attracted contributors, it quickly developed a life of its own and began to function largely independently' (Wikipedia 2012c). Something similar is happening in terms of promoting collaborative processes in Massive Open Online Courses (MOOC), which seem to threaten the traditional education model. This term was originally used to refer to the course organised by George Siemens and Stephen Downes, 'Connectivism and Connective Knowledge', in 2008 at the University of Manitoba (Canada). Participants used social networks to organise themselves, using various tools available in the network to enable collaborative work (McAuley, 2010: 21). There are many online tools to develop collaborative work, such as software packages that integrate work on a single project with many concurrent users connected through a network (Internet or intranet). (Ray, 2012). There are many software programs available in the network to facilitate group work. Examples include BroadVision Clearvale, Colaab, Google documents, Google Drive, Redmine, Teambox, Basecamp, Do.com, Wunderkit, Project-open and egroupware (Downes, 2012).

Nevertheless, educational institutions are currently offering different types of MOOCs. The XMOOC (Daniel, 2012) provides knowledge certifications through structured courses with materials given by teachers or, at least, discussion forums in which teachers answer questions. Tutoring for participants is often available. These courses maintain the open character of knowledge as well as the massive and online aspects, but they lose the initial nature of cMOOC. The latter allow a higher level of self-organisation on the part of the learning community. More recently, other institutions are organising MOOCs focused on specific tasks. Therefore, there are at least three different types of MOOCs, which are categorised according to emphasis on functionality and network connectivity (network-based), programming (task based) or course content (content based), (Lane, 2012). 
Perhaps the most important aspect of a MOOC is that learning and knowledge are the result of group interaction by means of technology. As Downes says, 'to learn in a connectivist course is to grow and develop, to form a network of connections in one's own [...] learning is not a matter of transferring knowledge from a teacher to a learner, but it is rather the product of the learner focusing and repeating creative acts, of practising something that is important and reflecting on this practice' (Downes, 2012: 11). From this perspective, learning and knowledge are not transferred from one network member to another, but rather the product of the creative acts of all members' interactions.

That was the key moment when the course $6.002 x$ becomes a VCBK. This behaviour has a significant meaning: it represents the transition to self-organisation, horizontal relationships, collaborative work to create knowledge and the creation of a true VCBK, which is the outcome of the network and its possibilities. The coming of VCBK is very important to be able to transform educational institutions; it has a great potential to transform institutions of knowledge and brings us closer to the new institutions of the knowledge society. In VCBK, knowledge is created by the group. The sense or meaning created is the product of the dialogue of the group (group cognition), (Stahl, 2006: 6). The element that makes the difference between the current and the past situation is the important role of technology or, if you prefer, of the tools that enable the interaction of members of a community of building knowledge. We may properly speak of intermediation enriched because the technology does not have a neutral role.

In modern society, there is not one singular model of sociability. In fact, today's society is characterized by complexity, pluralism and its diverse forms of social relationships. Today's society uses multiple channels of communication and, therefore, there are multiple ways of promoting sociability and social relations available. It is a society of numerous social interactions, which favours the creation of social identities. From the possible sources, the Internet stands out as a powerful communication tool. To what extent does this diversity of channels promote the diversity of identities? Perhaps it is too soon to know, since this is a relatively new phenomenon. The massive support possibilities for social interaction provided by new technologies date back barely a decade ago. But we can assume that the diverse interaction channels permit the intensification and social diffusion of new societal behaviours. These channels and interactions create a virtual space of sociability, with real life effects on human relations.

The existence of new forms of social interaction that are supported by new technologies, particularly the Internet, requires a new definition for the concept of community; this is a new community, a virtual community created over the Internet and with unprecedented operating characteristics: immediate and continuous connection, overcoming 
geographical distances, global dimensions, and supported by technological tools that maintain the memory of the relationship. Obviously, in some cases, the traditional characteristics of the community remain: shared values, emotional relationship, solidarity, socialization and mutual support. The novelty of the advent of virtual communities of social interaction is the existence of weaker links, due to their instantaneous membership, easy access and low commitment, all within the reach of the keyboard. Thus, this new model of sociability empowers individualism in the network, due to the fragile nature of the ties. This is clearly a paradoxical behaviour: the development of extreme individualism through the implementation of technological tools that strengthen social interaction.

In fact, what happens is that the multiple channels of social interaction promoted by the new technologies are creating a 'mixed socialization', where face-to-face and computerized communication complement one another and create a progressive hybrid (Georges 2010: 6). Youth, mainly, forms representations of the world based on face-toface and cybernetic relationships. For the new generations, there is a novel social narrative, a new discourse, a cultural convergence: the product of the combination of relationships that takes place in the space of the immediate and the digital technology (Deuze 2007). During this process, the real and the virtual combine to foster an extended and mixed communication (Georges 2010: 11), thus creating cultural convergence. The vision of the future is usually focussed on important functions of technological advances such as new materials, ICT, biotechnology, nanotechnology and cognitive sciences. The focus is on the purely technological change. Society, culture, values and even the mentality of people are considered a mere accompaniment, and that is in the best scenario. Sometimes, people are considered merely an inconvenience, something that slows down inevitable change, and, as Michio Kaku would say, products of 'the ancestral cave man' (2012: 15) that alienate us from the power of the gods, who, naturally, are on the side of technological development. However, from my point of view, the future depends on technological development and the development of man. The future must come from the co-evolution of a new transcendental consciousness of the person in symbiosis with technology, especially in the process of the creation of knowledge. The relationship between human knowledge and artificial intelligence requires a new theory, called Cognotechnology, whose most obvious practical expression is VCBK with technological support.

As indicated above, the network now promotes knowledge communities. Some communities spring spontaneously from the network itself and others are promoted by institutions. A project closely related to the concept of a virtual knowledge community is the FAO (Food and Agriculture Organization of the United Nations) project to create Thematic Knowledge Networks (TKN), (2009), which carried out actions of online 
knowledge generation related to food security and nutrition issues between 2006 and 2008. In this case, the initiative was created by the institution, which made hierarchical decisions. However, emerging Communities of Building Knowledge, with great potential for the future, are networks that arise out of the network itself, are initially deinstitutionalised, and have the characteristic of open knowledge.

\section{SOCIAL NETWORKS AS REAL TOOLS OF SOCIAL KNOWLEDGE CREATION}

Castells (2005) considers society to be structured in a borderless network. Taking this view, we can consider a global network of borderless networks. Under the concept of a social network, we can understand the web services in which users set some kind of social relationship using the Internet, which leads to the emergence of some kind of social structure. Social networks emerged in the US in the late 90 s, when sites such as Firefly and ICQ began to allow user interaction. In 2003, the phenomenon was popularised by the creation of Friendster, and Facebook, LinkedIn, Xing and Twitter have all emerged since then. As Cachia et al. (2007) maintain, whilst the relation between social capital and the Internet has been investigated by various studies, there is little work that applies the social capital approach to the field of social computing. Social computing refers to Internet applications, which on a basic level integrate networking and socialising.

The basis of the network society is the technological infrastructure and the organisational systems that enable the development of new forms of social relationships that could not be developed without the Internet. These new relationships are groups, and only in certain cases and circumstances do they become communities. In sociology, the term 'community' is of great importance; it differentiates, as Tönnies did, between the formal relations that are instrumental associations (Gesellschaft) and the links that are related to the constituent values of the community (Gemeinschaft). Currently, because everything is changing and we are living in a world out of control, new meanings of community and new forms of collective action and aggregation are emerging (Marinis et al., 2010). Certain intellectual debates that have taken place in recent years have ended by summarising the concept of community in the following way, 'especially when we are in a context of strong transformation because of the emergence of information and communication technology, which has an evident effect on the concept of community, such as the cybercommunity' (Ore and Seguel, 2010). A cybercommunity, paradoxically, may well reflect the ongoing individualisation. As Ridings et al. say, 'virtual communities can be defined as groups of people with common interests and practices that communicate regularly and for some time in an organised way over the Internet through a common 
location or mechanism. The location of the virtual community, although not physical, is important because it establishes the virtual "place" where the members meet'.

Despite the above statements, there are differences between social networks and communities. Communities (and cybercommunities) can be characterised and analysed by more than just the number of contacts among the members of the network. Communities are social networks defined by the quality of social bonds and by shared norms, conventions and meanings, that is, a set of common meanings and practices that create a shared semantic space (Rohde and Shaffer, 2004). Therefore, all virtual communities are social networks, but not all social networks are communities. An important question is 'what makes a person stay and participate in a virtual community?'. 'A community has a significant history, a shared cosmology, a common culture and a historical heritage, social interdependence and a reproduction cycle' (Barab and Duffy, 2000). In virtual communities, other features can be considered such as a common practice and common work, the opportunity to participate and interact, meaningful relationships, respect for diverse perspectives and views of minorities, and trust. Studies by Ridings et al. (82002) indicate that trust is a significant predictor of the virtual community members' desire to exchange information, and, especially, to obtain information. As we have seen, a network is not necessarily a community, but a community is always a network.

The independence of the members in relationships within the community is fundamental to our purpose. The network is not a set of subjects, but rather a set of relationships (Herrera and Barquero, 2012: 35). These relationships represent the social organisation in itself. To the extent that social organisation determines the flow of information and how knowledge is disseminated among the different groups, social organisation in itself can be perceived as a form of cognitive architecture. We use the concepts of learning and knowledge as parallel processes; however, there are differences between building knowledge and learning. Learning is an activity aimed at improving personal knowledge, while the construction of knowledge is a process focused on the development of ideas and collective knowledge; all members of the community have the capacity to create and develop knowledge (YaoHong et al., 2010: 4). Therefore, a learning community is a place where people share knowledge and cooperate in learning activities (Xiao and Carroll, 2006: 44).

\section{INTENSE VS. EPHEMERAL SOCIAL RELATIONSHIPS: THE NEW CULTURAL CONVERGENCE}

Virtual Internet communities are, in fact, communities. Clearly, they are different, and should be studied and analysed on the basis of sociological theories in order to 
demonstrate that they are really communities. The foundation of any community is the type of link that binds its members; while an association has instrumental relationships among its members. A community has a series of values, relationships and intentionality that gives the group its unique identity. Currently, during this time of great change, new definitions of community are emerging along with new modalities of action and collective aggregations. In today's world, individuals create their identities by establishing ephemeral social relationships, joining mobile collectives, communities that they seek and attempt to maintain alive, even for a moment, but not for extended periods of time.

There are differences between social networks and communities. A social network is defined by social ties, a group of individuals forming a network of contacts, since the members are and exist spatially and temporally in a relationship context; that is, there are referential and structural links among them and a relationship among the ties. Furthermore, a community has a significant 'personal' history, sharing a cosmology, a common culture, a historical inheritance, a social interdependence and a reproductive cycle (Barab et al. 2004: 4). Thus, for Rheingold, virtual communities are 'social aggregations that emerge from the network when a sufficient number of individuals establish public discussions over a sufficiently long period, with sufficient human sentiment to form personal relationship networks in cyberspace' (1993: 5). These virtual communities are based upon common interests. They have a large degree of heterogeneity in their social composition (Wellman, 2004) and are established in spaces of social relationships and creation of new identities.

The current construction of identity in individuals that are connected to a social network is conditioned by the cultural convergence of two channels of sociability: physical face-to-face relationships and virtual relationships on the Internet. Therefore, the digital identity is a representation of the individual based on the network activity, in a way quite similar to the physical identity. Furthermore, there is a great possibility that the online identity is coherent with the offline one (ONTSI 2011: 42). Contrary to the widespread opinion that the information provided on networks does not do justice to reality, the truth is that, in most cases, individuals connected to social networks prefer to reveal themselves as they really are, offering accurate information about their identity. They logically request the same from others. Studies on identity behaviour in networks reveal that when trying to construct and present profiles, the majority of young people feel that using their own photograph is 'the most logical' thing, since it reveals them 'as they really are', thus facilitating communication and strengthening the sense of dialogue or conversation of the virtual interactions. This reinforces the idea that the virtual relationship has similar characteristics to the face-to-face one. Probably, only a minority of 
individuals have an unusual criminal network behaviour. Social networks users positively value sincere communication and the revealing of someone's true identity. Youths connected to social networks make 'a great effort to present themselves as unique and as special individuals', identifying themselves with their own names and working to create a personal iconography' (Guadarrama and Gómez 2012).

\section{DATA AND APPROACH. SOCIAL NETWORK EXTENSION: AN INTERNATIONAL COMPARISON}

Based on the ubiquity of mobile phones, the introduction of mobile broadband services in most countries of the world, together with the availability of smartphones and tablet computers, has led to a sharp increase to mobile broadband subscriptions, which have experienced an average of $41 \%$ per annum since 2007 . The trend of traditional mobile services such as mobile Internet voice and SMS services and absorption is gradually changing data volumes of mobile voice traffic, with all it implies in terms of speed, price, available spectrum, income and investments. At the same time, fixed broadband Internet keeps constantly growing, although at lower rates in developing countries, where mobile broadband is meeting the demand for Internet access (ITU, 2012).

On the back of the increase in services throughout the world, particularly wireless broadband in developing countries, the number of people using the Internet increased $11 \%$ in the past year. At the end of 2011, more than one third of the world population was online, that is, 2.3 billion people. The growth of Internet users was greater in developing countries $(16 \%)$ than in developed countries $(5 \%)$. This reflects the large differences in penetration rates, 2011 finally stood at $70 \%$ in developed countries compared to $24 \%$ in developing countries. Penetration rates of Internet users in developing countries have tripled in the past five years, and most countries have increased the total number of Internet users worldwide, from $44 \%$ in 2006 to $62 \%$ in 2011. In developing countries, $30 \%$ of people under 25 use Internet, compared to $23 \%$ of people over 25 . At the same time, $70 \%$ of children - a total of 1.9 billion people - in developing countries is not online, which constitutes an enormous potential if developing countries succeed in schools and in the increasing of school enrolment rates. Throughout the world, the growth of Internet users has been between $8 \%$ and $10 \%$ in recent years; the geographic areas of Asia and the Pacific as well as the American continent are of particular interest, with two thirds of Internet users in the world. This year, Europe represents $16 \%$ of the usual Internet browsers. 
TABLE 1

Internet users. Millions of individuals 2005-2014

\begin{tabular}{lrrrrrrrrrr}
\hline & $\mathbf{2 0 0 5}$ & $\mathbf{2 0 0 6}$ & $\mathbf{2 0 0 7}$ & $\mathbf{2 0 0 8}$ & $\mathbf{2 0 0 9}$ & $\mathbf{2 0 1 0}$ & $\mathbf{2 0 1 1}$ & $\mathbf{2 0 1 2}$ & $\mathbf{2 0 1 3}$ & $\mathbf{2 0 1 4}$ \\
\hline Africa & 17 & 24 & 29 & 45 & 58 & 79 & 105 & 125 & 148 & 172 \\
Arab states & 26 & 36 & 44 & 55 & 66 & 81 & 94 & 121 & 137 & 152 \\
Asia and the Pacific & 344 & 394 & 503 & 615 & 726 & 872 & 988 & 1.113 & 1.205 & 1.310 \\
Commonwealth of & 29 & 35 & 47 & 55 & 67 & 95 & 115 & 128 & 143 & 158 \\
Independent States & & & & & & & & & & \\
Europe & 277 & 300 & 340 & 368 & 388 & 410 & 428 & 443 & 456 & 467 \\
The Americas & 316 & 346 & 385 & 405 & 428 & 473 & 519 & 556 & 597 & 639 \\
World & 1.009 & 1.134 & 1.348 & 1.543 & 1.731 & 2.012 & 2.249 & 2.487 & 2.686 & 2.898 \\
\hline
\end{tabular}

Source: ITU World Telecommunication/ICT Indicators database

The percentage of individuals that are Internet users and belong to social networks differs significantly between countries. For example, countries such as Brazil lead the global rankings of active users of social networks with $86 \%$, followed by Italy with $78 \%$. In this ranking, Spain holds a noteworthy third position (77\%). In Japan, the United States, the United Kingdom, France and Australia the percentage of active users of social networks ranges between $70 \%$ and $75 \%$. In Germany, it is $63 \%$, while in Switzerland it reaches 59\% (ONTSI 2011: 24). An initial assessment of this data suggests that Spain is within those countries having the largest percentage of individuals belonging to social networks. The extroverted nature of Spaniards and the importance of social relationships may be relevant, particularly considering that, generally speaking, these networks are believed to contribute positively towards maintaining and strengthening social relationships.

TABLE 2

Main social platforms in the world. Millions of users and percentage (2013)

\begin{tabular}{lccrrrr}
\hline & Facebook & Google + & Twitter & YouTube & LinkedIn & Instagram \\
\hline Asia Pacific & $296(35 \%)$ & $204(24 \%)$ & $191(23 \%)$ & $161(19 \%)$ & $71(8 \%)$ & $43(5 \%)$ \\
Europe & $138(49 \%)$ & $46(16 \%)$ & $48(17 \%)$ & $52(18 \%)$ & $17(6 \%)$ & $16(6 \%)$ \\
North America & $112(57 \%)$ & $33(17 \%)$ & $43(22 \%)$ & $52(26 \%)$ & $22(11 \%)$ & $21(11 \%)$ \\
Latin America & $70(58 \%)$ & $34(28 \%)$ & $27(23 \%)$ & $34(28 \%)$ & $15(12 \%)$ & $11(9 \%)$ \\
Africa and Middle & $21(62 \%)$ & $11(34 \%)$ & $12(36 \%)$ & $11(33 \%)$ & $7(20 \%)$ & $4(11 \%)$ \\
East & 637 & 328 & 322 & 311 & 132 & 95 \\
Total & & & & & \\
\hline
\end{tabular}

Source: GlobalWebIndex (GWI) 
As more and more people join the global information society and high-speed communication, networks become an indispensable infrastructure. According to ITU estimates (2013), mobile phone subscriptions were 6.8 trillion at the end of 2013 -almost as many as people on the planet. While the availability of ubiquitous mobile services is undeniable, approximately $100 \%$ of the population is covered by a mobile signal. By the end of 2013, there were 2.7 billion people using the Internet worldwide. In other words, there are still 4.4 billion people who are not online yet. The use of the Internet through wireless networks and devices will continue to grow strongly, accompanied or driven by greater supply of mobile applications and services in the markets. An important trend is the shift from voice to data traffic. Global mobile data traffic grew by $70 \%$ in 2012 , at a level which corresponds to almost 12 times all Internet traffic in 2000. Half of the traffic was video traffic. Mobile data traffic will grow at a CAGR of $66 \%$ from 2012 to 2017, reaching 11.2 exabytes per month in 2017. Traffic growth, mainly due to smartphones, is closely related to the diffusion of $4 \mathrm{G}$ services. In 2014, there were 3 billion Internet users. Throughout the world, Facebook is the main social network, followed by Google+, Twitter and YouTube; a bit further are the more specialized networks, such as LinkedIn, which has a mainly professional scope, and Instagram, a network designed for photo sharing (Table 4.2).

\section{CONCLUSION}

There is an emerging global intelligence, a global mind. The concept of semantic web refers to the quality of the data that exist in the network to be easily used and reused by users. That is, to transform existing data into information in the network so that it can be converted into knowledge. To do this, the computer system must have a level of 'understanding' of what is expected with the terms specified by the user. Tim Berners-Lee, founder of the website, says he hopes the new website will soon be able to analyse all data on the web, including content, links and transactions of people and computers. It is the semantic web that should make this possible, and it is emerging right now. When completed, our daily lives will be handled by machines talking to machines. The ubiquity of technology means that the technology will exist throughout our environment, and it will be interconnected, hence the great power of exponential growth. In the same way, the connection of human intelligence with communities of knowledge that increase the human intellect and social knowledge will arise.

The current status of the network approaches the future that Douglas Engelbart foresaw in which interconnected computers would increase the human intellect. The existing 
problems and the large number of variables and data in an increasingly complex society require new tools for decision-making. The task is how to use the network to support problem solving. The network increases the cognitive capacity of individuals by increasing human knowledge and intellect, which encourages interaction among members of Virtual Communities of Building Knowledge.

\section{REFERENCES}

Barab, S. A. and Duffy, T. (2000). «From practice fields to communities of practice», pp. 25-56 in D. Jonassen and S. M. Land (eds.) Theoretical foundations of learning environments. Mahwah, NJ: Lawrence Erlbaum Associates.

Barabasi, A. L. (2002). Linked: The New Science of Networks. Cambridge, MA: Perseus.

Brook B. et al. (2014). Assessing structural correlates to social capital in Facebook ego networks. Social Network. N. ${ }^{\circ}$ 38. Págs. 1-15.

Cachia, R., Kluzer, S., Cabrera, M., Centeno, C. y Punie, Y. (2007). ICT, Social Capital and Cultural Diversity, Sevilla: European Commission, Joint Research Centre, Institute for Prospective Technological Studies.

Castells, M. (2005). «The Network Society: From Knowledge to Polic» in M. Castells and G. Cardoso (eds.) The Network Society: From Knowledge to Policy. Washington, DC: Johns Hopkins Center for Transatlantic Relations.

Daniel, J. (2012). «Making Sense of MOOCs: Musings in a Maze of Myth, Paradox and Possibility». Retrieved abril 15, 2013, from: http://sirjohn.ca/wordpress/?page_ id $=29$

Debian (2004). Retrieved abril 15, 2013, from:http://www.debian.org/social_contract. es.html

Downes, S. (2011). «Access Futures». Retrieved abril 12, 2013, from http://www.cdlprojects.com/cmc11blog/wpcontent/uploads/2011/07/AccessFuture.pdf

Downes, S. (2012). «Connectivism and Connective Knowledge. Essays on meaning and learning networks», Retrieved abril 12, 2013, from:http://www.downes.ca/files/ Connective_Knowledge-19May2012.pdf.

Drucker, P. F. (1969). The Age of Discontinuity: Guidelines to Our Changing Society. New York: Harper \& Row.

Engelbart, D. C. (1962). «Aumenting human intellect: a conceptual Framework», SRI Project N. ${ }^{\circ}$. 3578, Retrieved abril 12, 2013, from: http://sloan.stanford.edu/mousesite/EngelbartPapers/B5_F18_ConceptFrameworkInd.html 
FAO (2009). «Report of the Review of the Pilot Phase of FAO Thematic Knowledge Networks». Retrieved abril 15, 2013, from: ftp://ftp.fao.org/docrep/fao/012/ak992e/ ak992e00.pdf

Herrera, M. y Barquero, J. D. (2012). Redes Sociales. De metáfora a Paradigma. Barcelona: Furtwangen Editores, Fundación Universitaria ESERP.

Himanen, P. (2005). «Challenges of the Global Information Society», pp. 337-371 in M. Castells, and G. Cardoso (eds.). The Network Society: From Knowledge to Policy. Washington: Johns Hopkins Center for Transatlantic Relations.

Kahneman, D. (2011). Thinking, Fast and Slow. London: Penguin Books.

Kaku, M. (2012). Physics of the Future. The inventions that will transform our lives. London: Penguin Books.

Lane, L. (2012). «Three kinds of moocs». Retrieved abril 15, 2013, from http://lisahistory.net/wordpress/2012/08/three-kinds-of-moocs/

Machlup, Fritz (1962). The Production and Distribution of Knowledge in the United States. Princeton University Press.

Marinis, P. de; Gatti, G. e Irazusta, I. (eds.). (2010). La comunidad como pretexto. En torno al (re)surgimiento de las sociedades comunitarias, Barcelona: Anthropos and Universidad Autónoma Metropolitana.

Marrero-Guillamón, I. (2012). «Descentrar el sujeto. Erving Goffman y la teorización del sujeto», Revista Internacional de Sociología, vol. 70, n. ${ }^{\text {2 } 2: 311-326 . ~}$

McAuley, A., Stewart, B., Siemens, G. y Cormier, D. (2010). «The MOOC model for digital practice». Retrieved abril 15, 2013 from: http:/www.elearnspace.org/Articles/MOOC_Final.pdf

Nonaka, I. y Konno, N. (1998). «The concept of "Ba": Building a Foundation of Knowledge Creation» California Management Review, vol. 40, N. . . 3: 40-54.

Nonaka, I.; Ryoko T. y Konno, N. (2000). «SECI, Ba and Leadership: a Unified Model of Dynamic Knowledge Creation» Long Range Planning 33: 534.

Ore, C. y Seguel, A. G. (2010). «La comunidad como excusa y el territorio como información: bordes sociales de la cibercomunidad», pp. 27-50 in Marinis, P. de; Gatti, G., Irazusta, I. (eds.) La comunidad como pretexto. En torno al (re)surgimiento de las sociedades comunitarias, Barcelona: Anthropos and Universidad Autónoma Metropolitana.

Pérez, C. (2005). Revoluciones tecnológicas y capital financiero: la dinámica de las grandes burbujas financieras y la época de bonanza, México: Siglo XXI.

Polanyi, M. (1983). The Tacit Dimension. Gloucester, Mass.: Peter Smith.

Ray, O. (2012). «Una docena de herramientas colaborativas para la gestión de proyectos». Retrieved abril 15, 2013 from: http://unadocenade.com/una-docena-de-herramientas-colaborativas-para-la-gestion-de-proyectos/ 
Ridings, C. M., Gefen, D. y Arinze, B. (2002). «Some antecedents and effects of trust in virtual communities», Journal of Strategic Information Systems, 11 (2002): 271295.

Rohde, M. y Shaffer, D. W. (2004). «Us, Ourselves, and We: Thoughts about Social (Self-) Categorization» pp. 18-23 in R. Klamma, M. Rohde, G. Stahl (eds.) SIG GROUP Bulletin. Introduction to the Special Issue on Community-Based Learning: Explorations into Theoretical Groundings, Empirical Findings and Computer Support. Workshop at the International Conference of the Learning Sciences (ICLS 2004). Los Angeles, California, USA: University of California at Los Angeles.

Small M. et al. (2015). «How stable is the core discussion network?» Social Network. N. ${ }^{\circ}$ 40. Págs. 90-112.

Stahl, G. (2006). Group Cognition. Computer Support for Building Collaborative Knowledge. Cambridge, MA (USA): The MIT Press.

Tapscott, D. (1995). Digital Economy. New York: McGraw-Hill.

Tapscott, D. y Williams, A. D. (2007). Wikinomics. How Mass Collaboration Changes Everthing. New York: Portfolio, Penguin Books.

Telefónica (2007). Sociedad de la Información en España. Madrid: Ariel/Fundación Telefónica.

Telefónica (2013). Sociedad de la Información en España. Madrid: Ariel/Fundación Telefónica.

w3schools.com (2013) retrieved abril 15, 2013, from: http://www.w3schools.com/ browsers/browsers_os.asp.

Wikipedia (2012a) retrieved abril 15, 2013 from http://stats.wikimedia.org/reportcard/ Xiao, L. y Carroll, J. M. (2006). «Fostering an informal learning community of computer technologies at school», pp. 36-60, in M. Rohde, V. Wulf, and G. Stahl (eds.) Behavior and Information Technology, Special Issue on «Computer Support for Learning Communities» Retrieved abril 15, 2013 from http://gerrystahl.net/pub/bit. pdf

YaoHong, H., Scardamalia, M. and Zhang, J. (2010). «Knowledge Society Network: Toward a Dynamic, Sustained Network for Building Knowledge», Canadian Journal of Learning and Technology (CJLT), vol. 36 (1) Fall/ autumn 2010. Retrieved abril 15, 2013 from http://cjlt.csj.ualberta.ca/index.php/cjlt/article/viewFile/579/282 Zubcsek P. et al. (2014). «Information communities: the network structure of communication». Social Network. N. ${ }^{\circ}$ 38. Págs. 50-62. 